\title{
A Brief Analysis of Sports Venues in Colleges and Universities
}

\author{
Zhongfeng Sun ${ }^{1}$ \\ ${ }^{1}$ Department of Physical Education, Qingdao University of Science \& Technology, Laoshan District, Qingdao, \\ Shandong, China \\ Correspondence: Zhongfeng Sun, Department of Physical Education, Qingdao University of Science \& \\ Technology, Laoshan District, Qingdao 266061, Shandong, China. E-mail: sunzhongfeng1976@163.com
}

Received: May 20, 2015 Accepted: June 11, 2015 Online Published: June 13, 2015

doi:10.5539/ass.v11n16p114 URL: http://dx.doi.org/10.5539/ass.v11n16p114

\begin{abstract}
Sports venue is the indispensable infrastructure of colleges and universities in sports, it occupies an important position. Sports venue embodies the sports teaching and recreational function between teachers and students in colleges and universities. In the course of China's reform and opening up, the depth and breadth of the market is increasing, the education system is changing gradually, and the management and operation of colleges and universities in our country is also gradually becoming market-oriented. In this context, the college sports venue is becoming the state of creating a certain economic value through market-oriented operation from the previous state without any output under administration construction funds. In our previous practice, the use of basic sports venue in Chinese universities is not in the market without playing the potential market value. While in the whole society, the construction of sports venues are expensive, and it is not realistic to ensure that each region has sports venue, so it is the result of the market for the colleges and universities to open the sports venues to the public, it not only can achieve the goal of the national fitness, but also can earn economic and market benefit for college sports venues. Whether can give full play to the market efficiency of sports venues and other facilities is a problem which college managers should think seriously.
\end{abstract}

Keywords: colleges and universities, sports venues, development, market, system

\section{The Current Situation of the Sports Venues in Colleges and Universities}

\subsection{The Investment in College Sports Venues Is Small}

In recent years Chinese universities have made considerable progress with the process of reform and opening up, the hardware construction of the sports venues still exists some shortcomings and deficiencies. There is large fixed investment in the special sports, but serious deficiency in the broad fundamental construction; this could not meet the needs of students and the population loving sports. Modern people increasingly pay attention to the health care function of sports, only the diversification of the sports facilities construction and reasonable open, can it be able to meet the various needs. Now, the sports venues and equipment in common colleges and universities are mostly more than ten years old, which need be upgraded to meet the requirements of modern people. More funds are needed to sports venues for students and the public health service.

\subsection{Lack of Innovation Consciousness in Idea}

Sports activities has become to a way and an indispensable part of people's life. The attitude has become to the exercise of lifelong sports from the former sightseeing, leisure. The public lack sports venues and facilities, the colleges and universities which have many ordinary resources also realize the problem gradually, and adopt a series of measures. Colleges and universities sports industry at present stage in our country is just in its infancy, problems in the developing process should be timely solved. We should seriously draw the experience of the developed country and area, formulate the public open communication strategy of university venues appropriate to the system of our country according to the actual situation of our country. Give full play to people's subjective initiative and innovate in the sports facility operation, only in this way, can it be improved.

\subsection{The System Is Not Perfect Enough}

The system here refers to management system and operation system, the school sports venues should be managed by a special management department and personnel, and the corresponding management system and operation scheme should be formulated. Specialized management personnel should not only know the school 
stadium usage, but also understand the demand of the market and the development direction. But the most experience of regular high college is no rules to follow, we need to sum up experience in the events, unify a theory and sum up a set of complete unity sports venues industry system to manage the ordinary university sports market. Along with the process of market economy constantly seeping into the colleges and universities, colleges and universities sports industry market is valued by economists and has a rapid development using the unique advantage of sports resources and sports audience. Due to the development of colleges and universities sports industry are not a certain rule, and its developing direction centers in the sports fitness and training, sports competition, venue rental aspect, the width of the development still has limitations and binding on the whole. This lead that the related industries cannot develop well, college sports special economic and social benefits have no better development.

\subsection{Business Operation Is Not Reasonable}

College sports venues have already begun to absorb the sports sponsors to promote the construction of college sports venues through sports sponsorship in the sports industry development trend. But the sponsors didn't realize the basic of sports development; they only pay attention to the economic benefits. Actually doing enterprise is doing culture, it will attract the public to participate in sports activities when we regard the sports as a kind of culture to promote. Colleges and universities need the talents who know both management and sports, so as to make full use of sports venue resources of colleges and universities, make a more reasonable business operation, and create the maximization of sports and wealth.

\section{Construct the New Operation Pattern of Sports Location Facility in Colleges and Universities}

Education system is becoming the development of all aspects from the education as the leading, colleges and universities also strengthened the training of sport athletes. At the same time, student sports association and the sports club develop continuously, recreational sports gradually form in and out school. All of these have put forward new requirements for professional management, such as safety, efficiency, maintenance, and venue environment, in the process of using of modern sports venues procedures. The physical culture and sports of our country in colleges and universities are in a nascent stage, it should adapt to the market operation of sports venues. The market operation of sports venues can help to cut school fiscal spending and be profitable for the school, it can also supply the funds for venues maintenance and equipment update in colleges and universities. It also has a powerful role in promoting the development of sports in colleges and universities and the national sports.

\subsection{The Protection of the Sports Venues}

Sports venues are the basis of the implementation of market-oriented operation. Sports venues is not an independent individual, the operation of sports venues maintain needs the co-management of real estate and sports departments, create a set of management means and methods adapt to the local. First of all, we need to clear the division of labor, coordinate the management responsibilities in college sports venues, such as infrastructure equipment maintenance, venue services, and environment maintenance. The most main is to do a good job in the security of venues, ensure every workers and service personnel to comply with the duties of their position, arouse the enthusiasm of each person's subjective, fully and rationally use the available commercialization resources in the school venues, do security work for the basis of the marketing operation. Secondly, we should make a reasonable arrangement in every area of the sports venues. Guarantee the school tasks of physical education teaching, sports training, student associations, at the same time, make a reasonable arrangement and planning for the spare time of the venues, make full use of the venue resources. College managers should realize the potential huge business opportunities of sports venues' marketization. Whether we can arrange the use of time reasonably and efficiently is the key to profitability of the sports venues. The managers should adopt informatization management when they manage the sports venues. The informatization management including plan management, charges and earnings management, setting reasonable tuition standard, software application management and capital management. Information management can realize time optimization processing and enhance the utilization of venues under the non-artificial factors. It can promote the marketization of sports venues to release the free time of venue to outside on a regular basis, and rule the stipulated time, equipment, costs of sports venues. In order to meet the needs of the public, we can also introduce new sports fitness equipment; the prophase investment can be earned during the later operation. This can not only appeal to the general public groups, but also can improve the market competitiveness in the same area to adapt to the need of market economy in the fierce competition. Finally, managers should play a positive influence factors, as a result that the sports venues management mode is not static, how to build a suitable management mode in this area and how to establish an sustainable development mechanism need the managers 
to make the right decision. Good predictability and the establishment of the crisis management consciousness can provide direction for college sports venues marketization. The purpose of planning decision, dynamic adjustment, treatment of dissolving, the staff training and other activities process which are able to deal with all kinds of crisis situation is to eliminate or reduce the threat and loss brought by the crisis. In order to correspond to the crisis in emergency and make damage fell to the lowest point, we should establish a system of prevention and treatment and the corresponding measures in advance.

\subsection{The Open of Sports Venues}

The development of sports has a broad mass base advantage, a video of the game can be sent instantly to all over the world by a variety of media, and sport is becoming more and more influential in all over the world. Nowadays, with the gradual increase in people's spiritual and cultural needs, the shortage of lack of sports leisure venues resources is surfacing. Then the country's ministry of culture, ministry of finance, administration of labor and sports commission departments jointly issued the notice on give full play to the utilization of sports venues, the notice points out that the use of the sports venues should be more fully, so that achieve the objectives of the profit. The scale of modern sports venues are able to host or sponsor a medium-sized game, as we all know, it is immeasurable to hold a competition for economic benefit and market effect, such as tickets, TV relay, and souvenirs. Colleges and universities should take the initiative to actively look for business opportunities, seeking for opportunities of the game. The economic benefits of hosting games can be used for maintaining sports venues and sports equipment. The market gain is invisible and huge wealth, it is a free advertising, and can also provide lessons for future competition. In March of 1986 national sports commission released the notice on the public sports venues should further improve the management and open to the masses positively, emphasized that the sports venues should be open to the public. College sports venues have the congenital advantage of open. Firstly, the planning and utilization of sports venues in the universities of our country has clear rules, sports facilities cannot be used for other purposes. Secondly, colleges and universities generally have advanced sports venues and sports facilities, and there is guarantee from schools and countries to make them have advantages in competition. Finally, the sports venues have excellent geographical location and environment, Chinese universities are generally in city or suburb, campus is beautiful and clean and the transportation is convenient. There are many residential communities, enterprises and institutions in the surrounding, the sports venues have the need to open and it is convenient to open.

\subsection{The Consumer Channels for Teachers and Students}

The consumption masses in our social fitness club and fitness places are mainly senior consumers, the main project club is fitness, and the sports varieties are single. With people's further understanding of sports, sports venues are needed in society to meet the needs of the consumers. College sports venues has comprehensive advantages, the use of the college sports venues can be positioned to the general public and school teachers and students, the collection of charges can be less than the fitness club, because fitness club service is for higher income groups, while colleges and universities venues face the whole public. Colleges and universities venues use consumer channel for teachers and students. Firstly, it can reduce the first large-scale advertising spending, the cut of consumer channels does not reduce consumption crowd, and every level of consumer groups have a lot of consumers. Secondly, the effect of sports venues open is propaganda, the teachers and students are good medium for advertising, word of mouth is able to speed up the marketization of sports venues. Finally, it also has a function of public welfare, college sports venues open can establish a good public image for to colleges and universities can expand the broad of college service, let the colleges and universities more popular among the crowd. College sports venues are an integral part of the infrastructure construction of colleges and universities, sports venues provide teaching place for colleges and universities, at the same time, it also provides leisure entertainment places for the teachers and students in their spare time. Along with our country's current social transition and the marketization reform deepening, and profound changes have taken place in the whole education system, the management and operation of colleges and universities is increasingly into the development track of market economy. In the process of colleges and universities coming into marketization from previous independent management, teachers and students' understanding on sports is deeper and deeper; the improvement of living standards makes sports within reach. Fitness places and sports instructors are the main lack for public, colleges and universities have the both advantages. Colleges and universities generally have more sports facilities and a high level of physical education teachers, physical education teachers in colleges and universities can play the role of coaching and sports instructors, providing technical guidance for the fitness of masses and the teachers and students.

\section{Summary}

To sum up, there are both opportunity and challenge in the marketization construction of our country ordinary 
university sports venues. Opportunity is whether we can accurately grasp the direction of sports venues development, and put the operation of sports venues into the society for the public to create social value. Challenge is that sports venues in colleges and universities have to face the harsh reality, it has qualitative difference with the sports venues in the society, as existing in colleges and universities, it is not a conventional property management. We need to meet the needs of the sports teaching in colleges and universities, and also need to be adapted to the market law of property management development. Colleges and universities should maintain the infrastructure equipment of sports venues and manage the venue services, environment maintenance systematically in a property management mode. The management of colleges and universities should arrange time reasonably, make full use of the sports venue, and complete the plan of sports teaching, training and competition at the same time of developing the paid open venue. The application of informatization management mode can not only shorten the time of the plan, but also can avoid the decision-making errors. It is a long-term solution for the marketization of sports venues to formulate reasonable charging standards, strict money management system and the long-term planning scientifically.

A self-improvement mechanism of sustainable development is established in order to realize the steady development of the college sports venues for contributing to the development of sports enterprise in our country, including the implementation of comprehensive quality management, the variable data appearing continuously in the process of management improvement, which make it adapt to school sports development and changes. Now there are a lot of management method of sports venues in our country's colleges and universities, mainly including contracting, leasing, management mode of college sports department, etc. There are different responsible for every kind of operation mode, the diversity of operation mode can cause the interesting of investors, investors have many choices, strong autonomy is also the characteristics of university sports venues.

The marketization operation of college sports venues can wake up the sleeping sports venues resource in a college. The reasonable allocation of resources can create revenue for colleges and universities and add new economic growth point. Increasing the funds spending on construction of sports facilities and maintaining sports venues can get a broader consumer groups and obtain more economic benefits. At the same time of meeting the exercise needs of the masses, the marketization operation can expand the reputation and market influence. It can not only promote the smooth implementation of the national fitness program, but also produce good social benefits, forming a virtuous circle of sustainable development. Besides, it can achieve double harvest of social and economic benefits to promote the process of marketization of sports venues in colleges and universities.

\section{References}

Huo, Q., \& Liu, D. F. (n. d.). The research on present situation and countermeasure of colleges and universities sports venue management. The 5th national conference on sports industry.

Liu, J. Z. (2009). A probe of management operations on college sports venues. China Market, (1).

Xia, X. L. (2006). The research on present situation and countermeasure of colleges and universities sports development in Zhejiang province. Journal of Beijing Sport University, (7).

$\mathrm{Xu}$, Y. et al. (2005). The research on utilization status and influence factors of ordinary university sports equipment resource. Journal of North China University of Technology Beijing China, (2).

Yang, Y. F. (2012). An analysis of college sports venues management pattern. Liaoning Sport Science and Technology, (3).

Zhu, L. (2002). Analysis and Research of Consumption Status Quo and Developing Trend of Physical Education in China. Sports Sciences Researches, 6(2).

\section{Copyrights}

Copyright for this article is retained by the author(s), with first publication rights granted to the journal.

This is an open-access article distributed under the terms and conditions of the Creative Commons Attribution license (http://creativecommons.org/licenses/by/3.0/). 